\title{
Prevalence of anemia among school-age children in Ethiopia: a systematic review and meta-analysis
}

\author{
Robel Tezera ${ }^{1 *}$, Zekariyas Sahile ${ }^{2}$, Delelegn Yilma², Equilnet Misganaw ${ }^{3}$ and Ermiyas Mulu²
}

\begin{abstract}
Background: Anemia continued to become a major public health problem in developing nations including Ethiopia. Especially, school children are more vulnerable for anemia and consequences of anemia. Generating accurate epidemiological data on anemia in school children is an important step for health policy maker. There are limited evidences on anemia prevalence in school-age children in Ethiopia. This study aimed to synthesize the pooled prevalence of anemia in school-age children in Ethiopia.

Methods: This systematic review and meta-analysis was followed the PRISMA guidelines. Comprehensive searched was conducted in PubMed/MEDLINE, Cochrane Library, Google Scholar, HINARI, and Ethiopian Journal of Health Development for studies published before 2016, supplemented by manual searches to identify relevant studies. Two review authors independently selected studies, extracted data, and assessed quality of studies. The Cochrane $Q$ test and $P^{2}$ test statistic were used to test heterogeneity through studies. The overall prevalence was calculated using random-effects model of DerSimonian-Laird method.

Results: From 831 obtained studies, 13 articles included in the meta-analysis. The pooled prevalence of anemia among school children in Ethiopia was $23 \%$ (95\% Cl 18-28\%). The prevalence of anemia in male and female school-age children was 27\% (95\% Cl 20 and 34\%) and 24\% (95\% Cl 18 and 30\%), respectively.

Conclusions: This study found that prevalence of anemia was a moderate public health problem in school children. Due to the complications of anemia for school children, preventative planning and control of anemia among school children in Ethiopia is necessary.
\end{abstract}

Keywords: Prevalence, Anemia, Iron-deficiency anemia, School children, Ethiopia

\section{Background}

Anemia is a public health problem both in developed and developing countries, including Ethiopia [1]. The causes of anemia are multifactorial [1-4]. Iron deficiency is the primary cause of anemia which results iron-deficiency anemia (IDA). However, it also coexists with malaria and parasitic infection [1,2]. Iron is an essential micronutrient and major cause of anemia, intrinsically found in every cells of human body and has several metabolic function including hemoglobin

\footnotetext{
* Correspondence: robeltezera@gmail.com

'Department of Medical Radiological Technology, Division of Public Health,

School of Medicine, Addis Ababa University, Addis Ababa, Ethiopia

Full list of author information is available at the end of the article
}

transport and storage, DNA synthesis, electron transport, and energy production [2-4].

According to the World Health Organization (WHO) report, anemia is the most common hematologic manifestation. Globally, around 1.62 billion people are affected by anemia that accounts more than $24.8 \%$ of the world population and from 30 to $50 \%$ of anemia was caused due to iron deficiency [1]. Iron-deficiency anemia (IDA) resulted 273,000 deaths in the world, and $97 \%$ of deaths were occurred in developing countries [5].

Studies have documented that rapid physical and physiological development makes school-age children more vulnerable for anemia, especially for IDA $[1,6,7]$. Based on WHO report, anemia affects 45.7 to $49.1 \%$ of school-age children in the world and prevalence of

(C) The Author(s). 2018 Open Access This article is distributed under the terms of the Creative Commons Attribution 4.0 International License (http://creativecommons.org/licenses/by/4.0/), which permits unrestricted use, distribution, and 
anemia among school-age children in Africa ranged from 64.3 to $71 \%$ [1]. Consequences of anemia on school-age children are poor psychomotor development, negative last-longing effects on central nervous system [8], poor IQ, poor school performance [9], reduced work capacity, and poor quality of life $[3,10]$. The economic impact is also significant; annually, more than US\$450 million loses in gross domestic product due to vitamin and mineral deficiencies in Ethiopia. However, scaling up micronutrient interventions would cost less than US\$51 million per year [11].

The risk factors for anemia are multifaceted including malaria, renal disease, and nutritional deficiency $[12,13]$. Studies also showed that schistosomiasis infection, hookworm infection, inherited disorders [13, 14], diarrhea, and fever in 6-59-month children [15] are associated with risk of developing anemia. Socio-economic factors like poverty, poor sanitation, low income, monotonous diet, parent's level of education, and community factors are also related with prevalence of anemia [13].

In Ethiopia, few evidences are available regarding the national magnitude of anemia among pre-school children and pregnant women. Ethiopia 2016 Demography Health Survey indicated that $56 \%$ of 6-59-month-old children were anemic [16]. There is limited recent information on national prevalence of anemia in school-age children in Ethiopia. National survey was conducted on prevalence of anemia among grade 3 and 4 children in 2000. But, the evidence was not recent, and data was collected only from grade 3 and 4 students. Hence, due to absence of recent and comprehensive systemic review about prevalence of anemia in school-age children in Ethiopia, we conducted meta-analysis in order to understand and explain the differences in various studies with age, sex, residence, and study period. Thus, the aim of this study is to review evidences regarding prevalence of anemia among school-age children in Ethiopia.

\section{Methods}

\section{Search strategy}

This systematic review and meta-analysis was performed according to the Preferred Reporting Items for Systematic review and Meta-Analysis (PRISMA) guidelines [17] (see Additional file 1: Table S1). We conducted extensive search in PubMed/MEDLINE, Cochrane Library, Google Scholar, HINARI, and Ethiopian Journal of Health Development for studies published before 2016. It was supplemented by manual searches to identify relevant unpublished studies. Search terms used included "Anemia" or "Hemoglobin," "school children," and "Ethiopia." We also screened reference list of included studies. This systematic review and meta-analysis was not registered with PROSPERO.

\section{Selection criteria}

All population-based studies which reported the prevalence of anemia among school children in Ethiopia using English language were included. The main outcome of interest was prevalence of anemia using the WHO criterion for anemia [4]. Ethiopian school-age children were considered as study population (5-17 years of age). Studies were excluded if they were not primary studies (such as review articles, conference abstract, editorials).

\section{Data extraction and quality assessment}

Two authors independently reviewed titles and abstract of included articles and reviewed full-text of the selected articles according to the eligibility criteria. Moreover, discrepancies between authors were resolved through discussion and consensus.

Data extractions were conducted by two authors independently. We resolved disagreement by verification and further discussion. The following data were extracted for analysis: author, publication year, survey period, setting of the study, sex, sample size, sample selection methods, number of children with anemia, and type of diagnostic criteria.

Quality assessment was conducted by two experts based on Hoy 2012 tool using 10 criteria addressing internal and external validity [18]. The items included (1) representation of the population, (2) sampling frame, (3) methods of participants' selection, (4) non-response bias, (5) data collection directly from subjects, (6) acceptability of case definition, (7) reliability and validity of study tool, (8) mode of data collection, (9) length of prevalence period, and (10) appropriateness of numerator and denominator. Each item was assessed as either low or high risk of bias. Unclear was regarded as high risk of bias. The overall risk of bias was then scored according to the number of high risk of bias per study: low $(\leq 2)$, moderate (3-4), and high $(\geq 5)$ (see Additional file 2: Table S2).

\section{Operationalization of variable}

The WHO criteria were used to determine hemoglobin (Hgb) cutoff point for anemia. Hgb levels lower than 11.5 and $12 \mathrm{~g} / \mathrm{dl}$ were considered as anemic for age ranges from 5 to 11 and 12-15 years old. Hgb level below $13 \mathrm{~g} / \mathrm{dl}$ was considered anemic for boys above 15 years of age [4].

\section{Statistical analysis and synthesis}

The statistical software Review Manager (RevMan) 5.3 was used for data analysis. The variance of anemia prevalence in each article was computed based on the binomial distribution formula by extracting the frequency sample size from published data [19]. Findings are illustrated in the form of forest plots and tables. Having used heterogeneity test, Cochran $Q$ ( $P$ value of less than 0.10 considered to be significant) and $I^{2}$ statistics (at least $50 \%$ 
considered to be significant) [20], we found significant variations between the study findings. Therefore, we used a random-effects model with $95 \%$ confidence interval (CI) for the estimations. Subgroup analysis was performed based on quality of included studies, sexes, urban/rural setting, and survey period.

Funnel plots analysis, Egger weighted regression and Begg rank correlation test were done to detect publication bias $(P<0.05$ was considered as suggestive of statistically significant publication bias) [20, 21].

\section{Results}

\section{Identified studies}

A total of 831 articles were retrieved by literature search (Fig. 1). Of these, 216 were excluded because of duplication, 596 did not relate to the aim of this meta-analysis, 6 did not meet eligibility criteria, and 13 were included in the meta-analysis.

\section{Description of included studies}

Twelve full-text articles and one abstract pertaining to the original articles were included in this systematic review and meta-analysis. Out 13 articles, 6 were conducted in the community setting [22-27]; remaining 7 articles were conducted in school setting [2, 6, 28-32]. The earliest study was conducted before 1993, but the exact period was not reported [32] and the latest was in 2016 [24]. All articles followed cross-sectional study design. Study population varied from 355 [23] to 14,740 [32] school-age children, between 5 and 19 years of old. A total of 22,104 school children were included in the study $(54.7 \%$ were male and $45.3 \%$ females). Overall information regarding prevalence of anemia were obtained from eight regions of Ethiopia: Addis Ababa [31, 32], Amhara [26, 33], Oromia [22, 27], Tigray [30], Southern region [6, 24], Somali [23], Harar [25, 29], and Afar [2] (Table 1).

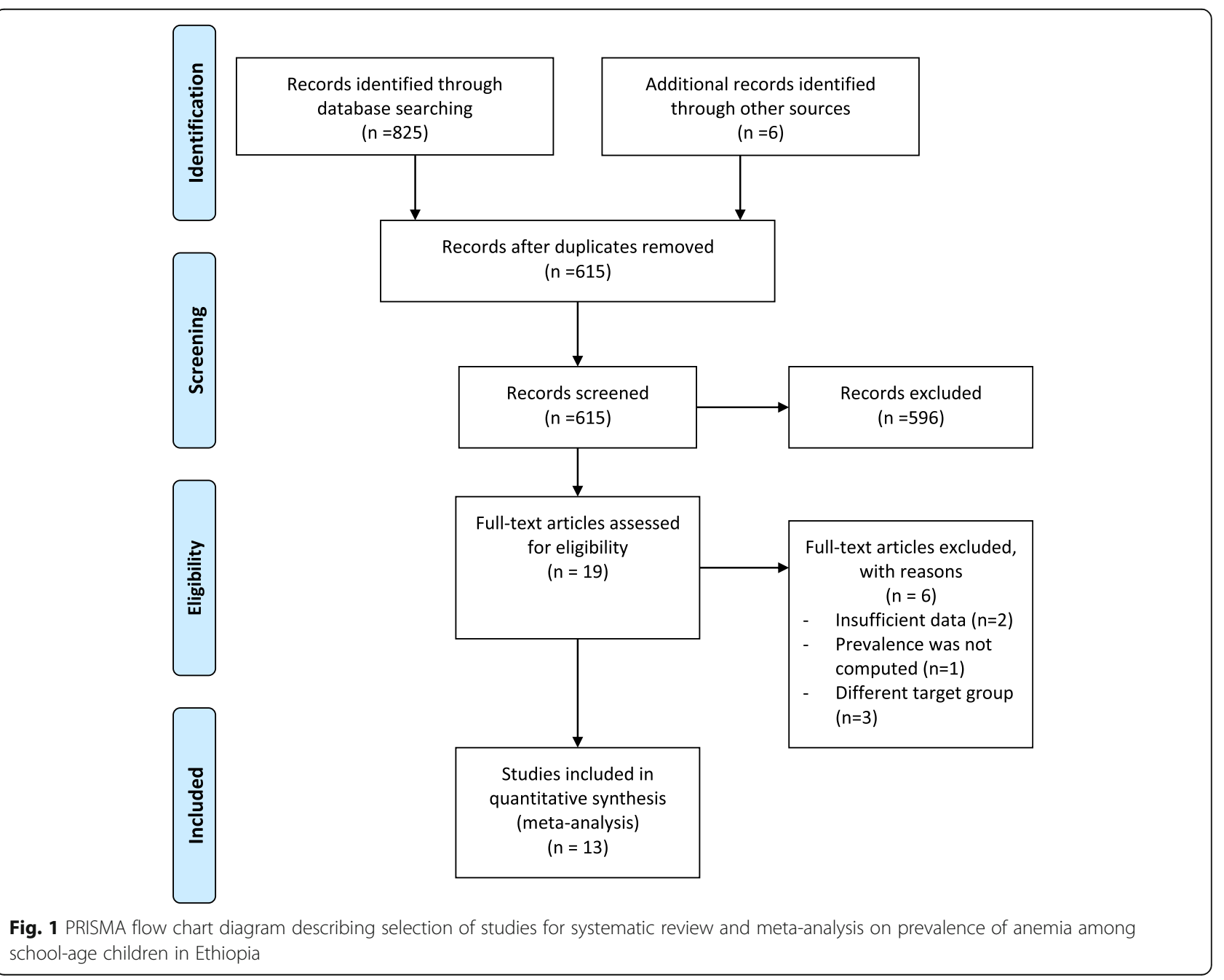


Table 1 Characteristic of included studies in systematic review and meta-analysis

\begin{tabular}{|c|c|c|c|c|c|c|c|c|c|}
\hline \multirow[t]{2}{*}{ Author } & \multirow[t]{2}{*}{$\begin{array}{l}\text { Survey } \\
\text { period }\end{array}$} & \multirow[t]{2}{*}{ Place of the study } & \multirow[t]{2}{*}{ Setting } & \multirow[t]{2}{*}{ Sample size } & \multirow[t]{2}{*}{$\begin{array}{l}\text { Sampling } \\
\text { procedure }\end{array}$} & \multirow{2}{*}{$\begin{array}{l}\text { Age } \\
\text { category } \\
\text { (years) }\end{array}$} & \multicolumn{2}{|c|}{$\begin{array}{l}\text { Anemia } \\
\text { (gender subgroup) }\end{array}$} & \multirow[t]{2}{*}{$\begin{array}{l}\text { Overall } \\
\text { prevalence (\% }\end{array}$} \\
\hline & & & & & & & Male (\%) & Female (\%) & \\
\hline $\begin{array}{l}\text { Wolde-Gebriel } \\
\text { et al. [32] } 1993\end{array}$ & $\begin{array}{l}\text { Not } \\
\text { reported }\end{array}$ & $\begin{array}{l}\text { Shoa region/ } \\
\text { Addis Ababa }\end{array}$ & Facility-based & 14,740 & $\begin{array}{l}\text { Simple random } \\
\text { sampling }\end{array}$ & $6-18$ & 21 & 15 & 18.6 \\
\hline $\begin{array}{l}\text { Mekasha and } \\
\text { Zerfu [31] } 2009\end{array}$ & 2003 & Addis Ababa & Facility-based & 707 & $\begin{array}{l}\text { Random cluster } \\
\text { sampling }\end{array}$ & - & - & - & 5.83 \\
\hline $\begin{array}{l}\text { Herrador et al. } \\
\text { [26] } 2014\end{array}$ & 2009 & $\begin{array}{l}\text { Libo Kemkem and } \\
\text { Fogera/Amhara }\end{array}$ & Community-based & 764 & $\begin{array}{l}\text { Multistage cluster } \\
\text { sampling }\end{array}$ & $4-15$ & - & - & 30.9 \\
\hline $\begin{array}{l}\text { Alelign et al. } \\
\text { [33] } 2015\end{array}$ & 2010 & $\begin{array}{l}\text { Durbeta town/ } \\
\text { Amhara }\end{array}$ & Facility (school) & 384 & $\begin{array}{l}\text { Multistage random } \\
\text { sampling }\end{array}$ & $5-15$ & 10 & 11 & 10.7 \\
\hline $\begin{array}{l}\text { Mahmud et al. } \\
\text { [30] } 2013\end{array}$ & 2010 & Tigray & Facility-based & 525 & $\begin{array}{l}\text { Systematic random } \\
\text { sampling }\end{array}$ & $6-15$ & 15 & 7 & 11 \\
\hline $\begin{array}{l}\text { Assefa et al. } \\
\text { [27] } 2014\end{array}$ & 2011 & Jimma Town/Oromia & Community-based & 404 & $\begin{array}{l}\text { Systematic random } \\
\text { sampling technique }\end{array}$ & $6-14$ & 41 & 35 & 37.6 \\
\hline $\begin{array}{l}\text { Mesfin et al. } \\
\text { [29] } 2015\end{array}$ & 2012 & Kersa/Harar & Facility-based & 1755 & $\begin{array}{l}\text { Simple Random } \\
\text { sampling }\end{array}$ & $5-14$ & 27 & 27 & 27.1 \\
\hline $\begin{array}{l}\text { Teji et al. } \\
\text { [25] } 2016\end{array}$ & $2012-2013$ & Babile district/Harar & Community-based & 547 & $\begin{array}{l}\text { Simple random } \\
\text { sampling }\end{array}$ & $10-19$ & - & 32 & 32 \\
\hline $\begin{array}{l}\text { Desalegn et al. } \\
\text { [22] } 2104\end{array}$ & 2013 & Jimma Town/Oromia & Community-based & 586 & $\begin{array}{l}\text { Multistage } \\
\text { randomsampling }\end{array}$ & $6-12$ & 40 & 36 & 43.7 \\
\hline $\begin{array}{l}\text { Gutema et al. } \\
\text { [23] } 2104\end{array}$ & 2013 & $\begin{array}{l}\text { Filtu Town/ } \\
\text { Somali region, }\end{array}$ & Community-based & 355 & $\begin{array}{l}\text { Systematic } \\
\text { Random Sampling. }\end{array}$ & $5-15$ & 28 & 19 & 23.66 \\
\hline $\begin{array}{l}\text { Adem et al. } \\
\text { [2] } 2015\end{array}$ & 2014 & Berahle district/Afar & Facility-based & 338 & $\begin{array}{l}\text { Multi stage } \\
\text { Random sampling }\end{array}$ & $14-19$ & - & 23 & 22.8 \\
\hline $\begin{array}{l}\text { Tesfaye et al. } \\
\text { [6] } 2015\end{array}$ & 2014 & $\begin{array}{l}\text { Bonga Town/ } \\
\text { Southern region }\end{array}$ & Facility-based & 408 & $\begin{array}{l}\text { Systematic } \\
\text { random sampling }\end{array}$ & $12-19$ & 9 & 19 & 15.2 \\
\hline $\begin{array}{l}\text { Chane et al. } \\
\text { [24] } 2016\end{array}$ & 2016 & $\begin{array}{l}\text { Mihur aklil district, } \\
\text { Gurage Zone/Southern }\end{array}$ & Community-based & 517 & $\begin{array}{l}\text { Systematic simple } \\
\text { random sampling }\end{array}$ & $5-10$ & 58 & 42 & 21.71 \\
\hline
\end{tabular}

\section{Risk of bias and heterogeneity}

Quality assessment was conducted for each study in ten different items using the risk of bias tool [18]. Of the 13 included studies, our summary assessment was low risk of bias for seven studies (53.8\%) [6, 22, 23, $25,29,30,33]$, moderate risk of bias for four studies $(30.8 \%)$ [2, 24, 26, 27], and high risk of bias for two studies $(15.4 \%)$ [31, 32].

The included studies exhibited high heterogeneity according to Cochrane $Q$ test $(Q$ test $p=0.00001)$ and $I^{2}$ test (98\%), which is indicative to using random-effects model. However, the Egger weighted regression statistics $(p<0.05)$ and Begg rank correlation statistics $(p=0.06)$ indicated no evidence of publication bias. There was no sign of publication bias and asymmetry in the funnel plot (see Additional file 3: Figure S3).

To reduce the heterogeneity, subgroup analysis was performed based on the quality of included studies, enrolment date of study, sexes, and urban/rural setting. Heterogeneity in rural studies was $78.0 \%$ and studies conducted from 2003 to 2011 year were $99.0 \%$ (Table 2). Nonetheless, the heterogeneity in all subgroups was considerable.
Table 2 Subgroup analysis of the prevalence of anemia by risk of bias, sex, urban/rural setting, and enrolment date of study using $\mathrm{chi}^{2}$ test for heterogeneity

\begin{tabular}{lllll}
\hline & Prevalence & $95 \% \mathrm{Cl}$ & $P$ value & $P^{2}(\%)$ \\
\hline Risk of bias & & & & \\
High risk & 0.13 & $0.00,0.25$ & 0.01 & 99.0 \\
Moderate risk & 0.28 & $0.22,0.34$ & 0.00 & 95.0 \\
Low risk & 0.23 & $0.15,0.32$ & 0.01 & 98.0 \\
Sex & & & & \\
Male & 0.27 & $0.20,0.34$ & 0.01 & 97.0 \\
Female & 0.24 & $0.18,0.30$ & 0.01 & 97.0 \\
Enrolment date of study & & & \\
2003-2011 & 0.19 & $0.09,0.30$ & 0.01 & 99.0 \\
2012-2016 & 0.27 & $0.20,0.33$ & 0.01 & 95.0 \\
Rural/urban setting & & & & \\
Rural & 0.33 & $0.26,0.40$ & 0.00 & 78.0 \\
Urban & 0.24 & $0.10,0.37$ & 0.03 & 98.0 \\
\hline
\end{tabular}




\section{Prevalence of anemia}

The prevalence of anemia among school-age children in Ethiopia varies from $5.83 \%$ of 707 school children in Addis Ababa [31] and $43.7 \%$ of 586 school children in Jimma town, southern region of Ethiopia [22]. The overall prevalence of the meta-analysis of 13 studies, according to the Der Simonian-Laird random-effects model, revealed that the pooled prevalence of anemia among school-age children in Ethiopia was 23\% (95\% CI 18-28\%) (Fig. 2). Meta-analysis of eight articles on severity of anemia revealed that, among anemic children, $61 \%\left(I^{2}=99 \%\right), 21 \%$ $\left(I^{2}=99 \%\right)$, and $11 \%\left(I^{2}=98 \%\right)$ had mild, moderate, and severe anemia, respectively.

Subgroup analyses showed that the prevalence of anemia among male school-age children in Ethiopia was $27 \%(95 \%$ CI $20 \%, 34 \%)$ and the prevalence of anemia among female school-age children was $24 \%$ (95\% CI 18\%, 30\%) which was estimated using 11 studies. Majority of the articles reported high prevalence in younger age category (5-9 years) $[6,12,24,29,34]$. Based on risk of bias, the 13 included studies were categorized into three: high risk of bias (16.3\%), moderate risk (30.6\%), and low risk (53.1\%). The prevalence of anemia in moderate risk studies (28\%; 95\% CI 22 and $34 \%)$ was higher than studies with high risk of bias (13\%; 95\% CI 0 and 25\%).

According to enrolment date of study, the 12 included studies were divided into two categories: studies conducted from 2003 to 2011 (58.2\%) and studies conducted from 2012 to 2016 (41.8\%). Prevalence of anemia was higher into the recent studies. According to residence, 6 included studies were divided into two categories: studies conducted in rural setting (20.75) and studies conducted in urban setting (79.25). The prevalence of anemia in rural setting (33\%; 95\% CI 29 and 36\%) was higher than studies conducted in urban setting (21\%; 95\% CI 20 and 23\%) (Table 2).

\section{Discussion}

The prevalence of anemia was varying from 5.83 to $43.7 \%$. The highest prevalence of anemia was reported in 2013 in Southwest Ethiopia (Jimma) [22]. The smallest prevalence was reported in 2009 among school children in Addis Ababa, Ethiopia [31]. In this study, we tried to estimate the overall prevalence of anemia among school going children in Ethiopia by reviewing the findings of available studies. The overall prevalence of anemia was $23 \%$. The result was higher from the national survey conducted in Ethiopia in 2000. The reason could be target population, geographical, and sample size variations. The national survey which was conducted in 2000 was included only grade 3 and 4 children. The 2000 national survey was conducted in 11 regions, and this meta-analysis was based on data form eight regions of Ethiopia. Our estimated pooled prevalence of anemia (23\%) was consistent with 2016 national survey (25.8\%) [35]; nonetheless, there were little age variations.

According to $\mathrm{WHO}$, anemia is a public health problem only when the prevalence exceeds $5 \%$ of the population. The WHO classification for mild, moderate, and severe is when its prevalence exceeds 5,20 , or $40 \%$, respectively [36]. Thus, the meta-analysis revealed moderate prevalence of anemia among school going children in Ethiopia. According to the WHO definition, five articles reported mild prevalence of anemia, seven articles reported moderate prevalence of anemia, and only one article reported severe prevalence of anemia. According to this review, anemia was a major public health problem for all population included in this study.

The result was similar with systematic review conducted in Africa (Some of the included countries are South Africa, Nigeria, Cote d'Ivoire, Uganda, Rwanda, Kenya, Botswana, and Burkina Faso). The systematic review reported that the majority of the articles reported moderate prevalence of anemia [34]. However, it was a

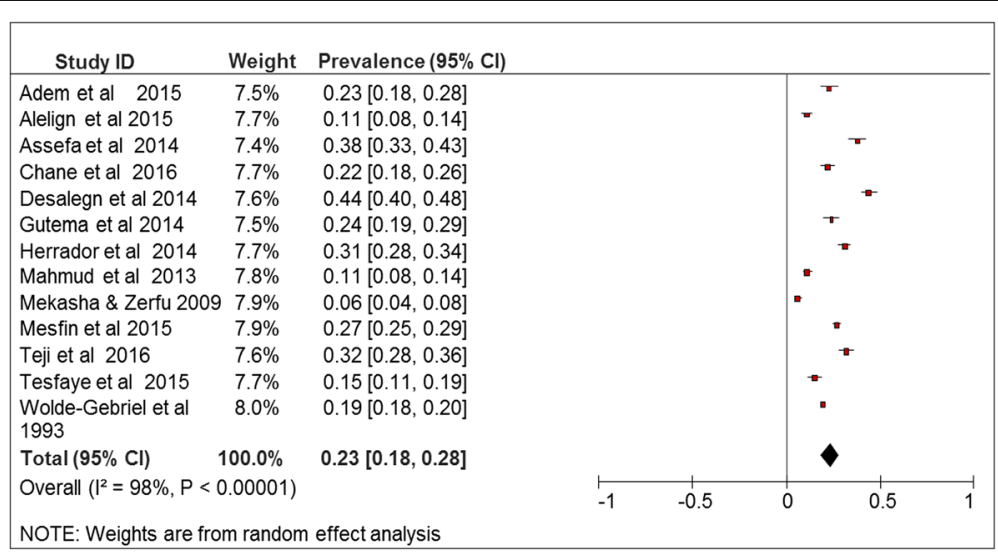

Fig. 2 Forest plot of 13 studies on prevalence of anemia among school-age children in Ethiopia, 2003-2016 
little bit a higher from the review conducted in South Africa. The highest prevalence reported in South Africa was $22 \%$ [37]. The reason could be geographical and socio-economic variations between the two countries.

In this study, male school-aged children had higher prevalence of anemia (28\%) compared with female counterparts (25\%). Though, there was no significant difference between the gender subgroups $(P=0.42)$. The potential explanation could be sample size, geographical, and research setting variations between included studies.

According to this review, anemia was a major public health problem for all population included in this study. The prevalence of anemia in Ethiopia depends on numerous factors such as socio-economic status, Hookworm and intestinal parasite infection, poor nutritional status, and inadequate food consumption [13, 36, 38]. A meta-analysis report shows that iron supplementation improves hematologic outcomes among primary school-aged children in low- or middle-income settings [39]. In addition, national fortification programs of micro-nutrients my help to reduce prevalence of anemia. Even with adequate iron intake, bioavailability of iron may reduce due to little consumption fruits and foods of animal region.

\section{Strengths and limitations}

The extensive searches using different database and different searching strategy (manual and electronic) were the strength of this study. Data extraction was also conducted using pre-determined tool and was extracted by two authors independently to minimize bias. The study also reviewed potential risk factors for anemia. Quality assessment was also conducted by two independent authors, and all the included studies had moderate and high quality.

There are potential limitations to this study. The data were obtained from eight regions of Ethiopia, which comprises around 2.5 million target population. However, the analyzed pooled prevalence may not fully represent the prevalence of anemia in Ethiopia because there is lack of evidences in some parts of the country. Only $\mathrm{Hb}$ measurement and WHO cutoff point was used to determine status of anemia. Because of small sample size, meta-regression was not conducted to identify statistical deference between different regions of Ethiopia. Meta-analysis was also conducted by excluding poor research setting; however, the result $(25 \%)$ was not significantly different from the overall prevalence $(P=0.36)$.

High heterogeneity was recorded (large $I^{2}$ and small $P$ value) among included studies. The source of high heterogeneity could be because the studies were conducted in different regions of Ethiopia. High heterogeneity was addressed by using random-effects model to compute pool prevalence. Random-effects model considers any heterogeneity embedded in meta-analysis.

\section{Conclusion}

This systematic review and meta-analysis revealed moderate prevalence of anemia among school-age children in Ethiopia. Thus, adequate intervention should be designed by policy makers, health care community, and researcher to alleviate the problem. Further studies should be conducted to accurately determine potential risk factors for high prevalence of anemia.

\section{Additional files}

Additional file 1: Table S1. PRISMA Checklist. (PDF 203 kb)

Additional file 2: Table S2. Risk of bias assessment of included studies using the Hoy 2012 tool. (XLSX $12 \mathrm{~kb}$ )

Additional file 3: Figure S3. Funnel plot of 13 studies on prevalence of anemia among school-age children in Ethiopia, 2003-2016. (WMF 2 kb)

\section{Abbreviations}

$\mathrm{Cl}$ : Confidence interval; Hgb: Hemoglobin; IDA: Iron deficiency anemia; PRISMA: Preferred Reporting Items for Systematic Review and Meta-Analysis; RevMan: Review manager; WHO: World Health Organization (WHO)

\section{Acknowledgements}

We are deeply grateful for Bahr Dar University for the unreserved support. We also thank Mr. Tadele Andargie for critical review of the document.

\section{Availability of data and materials}

The datasets generated and/or analyzed during the current study are available from the corresponding author on reasonable request. Additionally, few data generated or analyzed during this study are included in this published article [and its supplementary information files].

\section{Authors' contributions}

RT and ZS originally designed the systematic review and meta-analysis. RT and ZS equally contribute in study searching and selections. RT, ZS, DY, EMA, and EMK equally contribute in data extraction and data analysis. RT and DY equally contribute in quality assessment. RT, ZS, DY, EMA, and EMK equally contribute in report write-up. All authors read and approved the final manuscript.

Ethics approval and consent to participate

Not applicable.

\section{Competing interests}

The authors declare that they have no competing interests.

\section{Publisher's Note}

Springer Nature remains neutral with regard to jurisdictional claims in published maps and institutional affiliations.

\section{Author details}

'Department of Medical Radiological Technology, Division of Public Health, School of Medicine, Addis Ababa University, Addis Ababa, Ethiopia.

${ }^{2}$ Department of Public Health, College of Health Science and Medicine, Ambo University, Ambo, Ethiopia. ${ }^{3}$ Human Resources for Health $(\mathrm{HRH})$ Department, JHPIEGO/Ethiopia, Addis Ababa, Ethiopia.

Received: 13 September 2017 Accepted: 9 May 2018

Published online: 24 May 2018

\section{References}

1. Benoist BD, McLean E, Egll I, Cogswell M. Worldwide prevalence of anaemia 1993-2005: WHO global database on anaemia. Geneva: WHO global database on anaemia; 2008.

2. Adem OS, Tadsse K, Gebremedhin A. Iron deficiency aneamia is moderate public health problem among school going adolescent girls in Berahle district, afar, Northeast Ethiopia. J Food Nutr Sci. 2015;3:10-6. 
3. Charles CV. Iron deficiency Anemia. In: Maddock PJ, editor. A public health problem of global proportions; 2012. Public Health - Methodology, Environmental and Systems Issues.

4. World Health Organization. Iron deficiency anaemia: assessment, prevention and control. A guide for programme managers. Geneva: World Health Organization; 2001

5. Mathers C, Steven G, Mascarenhas M. Global health risks: mortality and burden of disease attributable to selected major risks. Geneva: World Health Organization; 2009

6. Tesfaye M, et al. Anemia and iron deficiency among school adolescents: burden, severity, and determinant factors in Southwest Ethiopia. Adolesc Health Med Ther. 2015;6:189-96.

7. Pasricha S-R, et al. Control of iron deficiency anemia in low- and middleincome countries. Blood J. 2013;121(14):2607-17.

8. Walter T. Effect of iron-deficiency anemia on cognitive skills and neuromaturation in infancy and childhood. Food Nutr Bull. 2003;24(4):104-10.

9. Grantham-McGregor S, Ani C. A review of studies on the effect of iron deficiency on cognitive development in children. J Nutr. 2001;131:649-66.

10. Grein. The cognitive effects of iron deficiency in non-anemic children. Nutr Noteworthy. 2001;4(1):1-6.

11. UNICEF, Micronutrient Initiative. Vitamin and mineral deficiency: a global progress report. Ottawa: Mironutrient Initiative and UNICEF; 2004.

12. Kassebaum NJ, et al. A systematic analysis of global anemia burden from 1990 to 2010. Blood J. 2014;123(5):615-24.

13. Sanou D, Ngnie-Teta I. Risk factors for anemia in preschool children in SubSaharan Africa. Ottawa: Research Gate; 2012. p. 171-89.

14. Tolentino K, Friedman JF. An update on anemia in less developed countries. Am J Trop Med Hyg. 2007;77(1):44-51.

15. Semba RD, et al. Diarrhea and fever as risk factors for anemia among children under age five living in urban slum areas of Indonesia. Int J Infect Dis. 2008;12:62-70.

16. Central Statistical Agency (CSA) [Ethiopia] and ICF. Ethiopia demographic and health survey 2016: key indicators report. Addis Ababa and Rockville: CSA and ICF; 2016.

17. Moher D, et al. Preferred reporting items for systematic reviews and metaanalyses: the PRISMA statement. PLoS Med. 2009:6(7):e1000097.

18. H D, et al. Assessing risk of bias in prevalence studies: modification of an existing tool and evidence of interrater agreement. J Clin Epidemiol. 2012; 65(9):934-9.

19. Altman, D. Practical statistics for medical research. 1991

20. Higgins J. In: Green S, editor. Cochrane handbook for systematic reviews of interventions version 5.1.0. Southern Gate: The Cochrane Collaboration; 2011.

21. Egger M, Smith GD, Schneider M. Bias in meta-analysis detected by a simple, graphical test. BMJ. 1997;315:629.

22. Desalegn A, Mossie A, Gedefaw L. Nutritional iron deficiency anemia: magnitude and its predictors among school age children, Southwest Ethiopia: a community based cross-sectional study. PLoS One. 2014;9(12):2-13.

23. Gutema B, et al. Anemia and associated factors among school-age children in Filtu Town, Somali region, Southeast Ethiopia. BMC Hematol. 2014;14(13):1-6.

24. Chane $\mathrm{H}$. Magnitude of anemia and its contributing factor among school age children in Mihur Aklil district, Gurage zone, Ethiopia. Addis Ababa: Addis Ababa University, Addis Ababa University Press; 2016. p. 80.

25. Teji K, et al. Anaemia and nutritional status of adolescent girls in Babile District, Eastern Ethiopia. Pan Afr Med J. 2016;24(62):1-10.

26. Herrador $Z$, et al. Micronutrient deficiencies and related factors in schoolaged children in Ethiopia: a cross-sectional study in Libo Kemkem and Fogera Districts, Amhara Regional State. PLoS One. 2014;9(12):1-20.

27. Assefa S, Mossie A, Hamza L. Prevalence and severity of anemia among school children in Jimma Town, Southwest Ethiopia. BMC Hematol. 2014; 14(3):2-9.

28. Wassie TA. Study of the Association of Soil-Transmitted Helminthiasis with malnutrition and anemia among school children, Debub Achefer District, Northwest Ethiopia. Addis Ababa: Addis Ababa University, Addis Ababa University Press; 2010. p. 1-82.

29. Mesfin F, Berhane $Y$, Worku A. Anemia among primary school children in Eastern Ethiopia. PLoS One. 2015;10(4):1-10.

30. Mahmud MA, et al. Risk factors for intestinal parasitosis, anaemia, and malnutrition among school children in Ethiopia. Pathog Glob Health. 2013; 107(2):58-65.
31. Mekasha A, Zerfu M. Prevalence of anemia among school children in Addis Ababa. Ethiop Med J. 2009:47(2):129-33.

32. Wolde-Gebriel Z, et al. Interrelationship between vitamin A, iodine and iron status in schoolchildren in Shoa Region, Central Ethiopia. Br J Nutr. 1993;70: 593-607.

33. Alelign T, Degarege A, Erko B. Prevalence and factors associated with undernutrition and anaemia among school children in Durbete Town northwest Ethiopia. Arch Public Health. 2015;73(34):1-7.

34. Best $C$, et al. The nutritional status of school-aged children: why should we care? Food Nutr Bull. 2010;31(3):400-17.

35. Ethiopian Public Health Institute. Ethiopian national micronutrient survey report. Addis Ababa: EPHI; 2016.

36. WHO. The global prevalence of anaemia in 2011. Geneva: World Health Organization; 2015.

37. Visser J, Herselman M. Anaemia in South Africa: the past, the present and the future. S Afr J Clin Nutr. 2013;26(4):1-2.

38. Best $\mathrm{C}$, et al. Can multi-micronutrient food fortification improve the micronutrient status, growth, health, and cognition of schoolchildren? A systematic review. Nutr Rev. 2011;69(4):186-204.

39. Low $M$, et al. Effects of daily iron supplementation in primary-school-aged children: systematic review and meta-analysis of randomized controlled trials. CMAJ. 2013;185(17):E791-802.

\section{Ready to submit your research? Choose BMC and benefit from:}

- fast, convenient online submission

- thorough peer review by experienced researchers in your field

- rapid publication on acceptance

- support for research data, including large and complex data types

- gold Open Access which fosters wider collaboration and increased citations

- maximum visibility for your research: over $100 \mathrm{M}$ website views per year

At BMC, research is always in progress.

Learn more biomedcentral.com/submissions 